\title{
Geociências
}

\section{A qualidade das águas na região dos garimpos de topázio imperial na sub-bacia do rio da Ponte, Ouro Preto-MG}

\author{
(Water quality in the topaz prospecting area of the Ponte River \\ sub-basin, Ouro Preto - MG)
}

\author{
Aline Kelly Guimarães-Silva \\ Depart.de Geologia, Escola de Minas, Univ.Federal de Ouro Preto.E-mail: alinechemy@gmail.com
}

Daniela Alcântara Machado

Depart.de Geologia, Escola de Minas, Univ. Federal de Ouro Preto.E-mail: daniourop@yahoo.com.br

Hermínio Arias Nalini Jr

Depart.de Geologia, Escola de Minas, Univ.Federal de Ouro Preto.E-mail: nalini@degeo.ufop.br

Jorge Carvalho de Lena

Depart.de Geologia, Escola de Minas, Univ.Federal de Ouro Preto.E-mail: jorge.delena@degeo.ufop.br

\section{Resumo}

Na região de Ouro Preto observa-se significativa presença de garimpos de topázio. Essa atividade caracteriza-se pela utilização de técnicas rudimentares e sem controle de descarte dos rejeitos. Entre os danos causados ao meio físico e biótico estão o desmatamento; geração de pilhas de rejeito, aumento expressivo da concentração de finos transportados e assoreamento dos cursos d'água. Nesse trabalho foi realizado um estudo hidrogeoquímico para avaliar a qualidade das águas do rio Ponte e seus principais tributários, localizados no distrito de Rodrigo Silva, importante produtor de topázio imperial na região de Ouro Preto. Amostras de água foram analisadas para $\mathrm{pH}$, Eh, oxigênio dissolvido, condutividade elétrica, turbidez, alcalinidade, cloretos, sulfatos, metais (Al, As, Ba, $\mathrm{Ca}, \mathrm{Cd}, \mathrm{Co}, \mathrm{Cr}, \mathrm{Cu}, \mathrm{Fe}, \mathrm{K}, \mathrm{Li}, \mathrm{Mg}, \mathrm{Mn}, \mathrm{Mo}, \mathrm{Na}, \mathrm{Ni}, \mathrm{Sc}, \mathrm{Sr}$, Ti, V, Y e Zn) e material particulado em suspensão. Os resultados mostram que o principal problema da área são os altos valores de turbidez, que estão associados à presença de sólidos em suspensão introduzidos pelo garimpo (chegando a 2,9 g.L $\mathrm{L}^{-1}$ ). Esse material representa uma fase importante capaz de carrear metais no compartimento aquático.

Palavras-chave: Águas, metais, material particulado em suspensão, garimpos de topázio.

\begin{abstract}
Around the Ouro Preto region, State of Minas Gerais Brazil, there is a significant presence of topaz prospecting. This activity is characterized by the use of rudimentary techniques without any tailing disposal control. Among the environmental impacts are: deforestation, tailing generation and accumulation, introduction of suspended fine particulate matter to the water and silting up of streams. In this work a hydrochemical study was carried out aiming to assess the water quality of the Ponte River and its tributaries. Water samples were analyzed for $\mathrm{pH}$, Eh, dissolved oxygen, electrical conductivity, turbidity, alkalinity, chloride, sulfate, metals (Al, As, Ba, Ca, Cd, Co, Cr, Cu, $\mathrm{Fe}, \mathrm{K}, \mathrm{Li}, \mathrm{Mg}, \mathrm{Mn}, \mathrm{Mo}, \mathrm{Na}, \mathrm{Ni}, \mathrm{Sc}, \mathrm{Sr}, \mathrm{Ti}, \mathrm{V}, \mathrm{Y}$ and $\mathrm{Zn}$ ) and suspended particulate matter. The results show that the main problem in the area is the high turbidity values, which are associated with the presence of suspended solids introduced by the prospecting activity (reaching a concentration of up to $\left.2.9 \mathrm{~g} \cdot \mathrm{L}^{-1}\right)$. This fact represents an important facto, since it demonstrates that metals are being deposited in the aquatic atmosphere.
\end{abstract}

Keywords: Water, metals, particulate suspended matter, topaz prospecting. 


\section{Introdução}

O Quadrilátero Ferrífero é uma área com grandes reservas minerais caracterizando-se por intensa atividade mineradora, podendo-se destacar as várias ocorrências de topázio em sua porção sudeste no município de Ouro Preto. A sub-bacia do rio da Ponte, localizada entre os municípios de Ouro Preto e Ouro Branco (Figura 1), representa um dos focos com presença significativa de atividade garimpeira, com lavras de pequena a grande escala. As lavras em pequena escala caracterizam-se por garimpos ao longo do rio, onde se encontram centenas de garimpeiros trabalhando com técnicas rudimentares e sem controle de descarte dos rejeitos, dada a incapacidade de investimento do garimpeiro. Nas lavras em grande escala, a extração é mecanizada, como na mina de Capão do Lana, no distrito de Rodrigo Silva, distante $25 \mathrm{~km}$ da sede do município de Ouro Preto (Guimarães, 2005).

Os danos ao meio físico e biótico causados pelos garimpos são facilmente identificados e encontram-se descritos na literatura (Peixoto \& Lima, 2004), como, por exemplo: desmatamento; geração de pilhas de rejeito, sujeitas ao escoamento superficial e transporte de sólidos sedimentáveis; aumento expressivo da concentração de finos transportados e, conseqüentemente, do nível de turbidez; assoreamento, entre outros.

Os garimpos de topázio envolvem processos de extração puramente físicos, com desmonte de material geológico, dragagem, peneiramento e revolvimento de material. Uma das influências desses garimpos é o fornecimento de material particulado para os ecossistemas aquáticos. Este material particulado em suspensão (MPS) está sujeito a uma série de processos físicos e químicos que podem promover direta ou indiretamente a liberação e/ou acúmulo de contaminantes metálicos ao longo de um sistema fluvial.

O rio da Ponte tem suas nascentes no distrito de Rodrigo Silva, sendo formado após as confluências dos córregos Mato da Roça, Papa-Cobra e Lavri- nha, três de seus principais tributários. $\mathrm{O}$ rio da Ponte representa uma das contribuições da Represa de Tabuão, construída em 1956 para o fornecimento de energia elétrica para uma fábrica de alumínio em Ouro Preto, cujas águas e sedimentos foram objetos de estudos geoquímicos recentes (Guimarães, 2005).

A área de estudo caracteriza-se por uma região de nascentes e presença de garimpos com revolvimento constante de material e utilização de dragas que aumentam a concentração de sólidos em suspensão e espécies metálicas no compartimento aquático. Assim, em função de suas características geológicas e pela presença dos garimpos, a área proposta para estudo pode-se caracterizar como uma área de potencial risco para a biota e a saúde humana.

Esse trabalho tem por objetivo a investigação das concentrações de metais traço e maiores em amostras de água da sub-bacia do rio da Ponte e a avaliação da influência dos garimpos na geoquímica das águas.

\section{Materiais e métodos}

O trabalho foi realizado em 18 sítios amostrais (Figura 1), selecionados de acordo com a acessibilidade e localização dos garimpos ao longo do rio. As amostras de água foram coletadas no canal ativo do rio, buscando-se seções com fluxo uniforme, evitando confluências das drenagens, zonas de turbulência e remanso. As determinações in situ incluíam parâmetros físico-químicos como pH, Eh, Condutividade Elétrica (CE), obtidas com um multiparâmetro Myron (Ultrameter modelo 6P), e Oxigênio Dissolvido (OD), obtido com um oxímetro Schott (modelo handylab OX 1/ SET). Os instrumentos foram ajustados de acordo com instruções do fabricante. Amostras para determinação de alcalinidade, cloreto e sulfato foram coletadas em frascos de polietileno de 1 litro e levadas ao Laboratório de Geoquímica Ambiental (LGqA/DEGEO/UFOP) para determinação dos parâmetros físico-químicos. Amostras para determinação de metais (maiores e traço) foram coletadas em frascos de polietileno de $30 \mathrm{~mL}$ e aciduladas com adição de $\mathrm{HNO}_{3}$ concentrado até $\mathrm{pH}<2$. Todas as amostras foram conservadas à temperatura de $4^{\circ} \mathrm{C}$ até o momento da análise. As determinações dos parâmetros físico-químicos foram realizadas de acordo com Greenberg et al. (1992) - alcalinidade e cloreto por titulação e sulfato pelo método turbidimétrico utilizando um equipamento Micronal modelo B250. A determinação de $\mathrm{Al}, \mathrm{As}, \mathrm{Ba}, \mathrm{Ca}, \mathrm{Cd}, \mathrm{Co}, \mathrm{Cr}, \mathrm{Cu}, \mathrm{Fe}, \mathrm{K}, \mathrm{Li}$, Mg, Mn, Mo, Na, Ni, Sc, Sr, Ti, V, Y e Zn foi realizada por ICP OES (Spectro, Modelo Ciros CCD, visão radial) do Laboratório de Geoquímica Ambiental (LGqA/DEGEO/UFOP). Todos os resultados foram verificados com o material de referência NIST-SRM 1643e.

A estimativa da quantidade de material em suspensão foi feita filtrando-se cerca de $250 \mathrm{~mL}$ de amostra com membranas de $0,45 \mu \mathrm{m}$. As membranas de acetato de celulose com o material particulado retido foram pesadas em balança analítica com precisão de $\pm 1 \mathrm{mg}$, após procedimento de secagem a $55 \pm 5^{\circ} \mathrm{C}$ até obtenção de massa constante. A determinação da massa de material retido foi feita descontando-se a massa seca média da membrana de acetato de celulose.

\section{Resultados e discussão \\ Propriedades físico químicas}

O pH e Eh são duas variáveis importantes no ecossistema aquático, pois são capazes de determinar a dissolução, precipitação, oxidação e redução de várias substâncias (Bour \& Loch, 1995; Gill, 1996; Weiner, 2000). As amostras da subbacia do rio da Ponte apresentam valores de $\mathrm{pH}$ entre 6,15 - 7,50 (estação de seca - Tabela 1) e 5,93 - 7,71 (estação das chuvas - Tabela 2). Esses valores encontram-se dentro da faixa estabelecida pela Resolução CONAMA Nº 357 (pH 6,0 $9,0)$. Os valores de Eh apresentam-se entre 113 - $223 \mathrm{mV}$ (estação de seca) e 145 - 238 mV (estação das chuvas), compatíveis com um ambiente de corrente. 
Aline Kelly Guimarães-Silva et al.

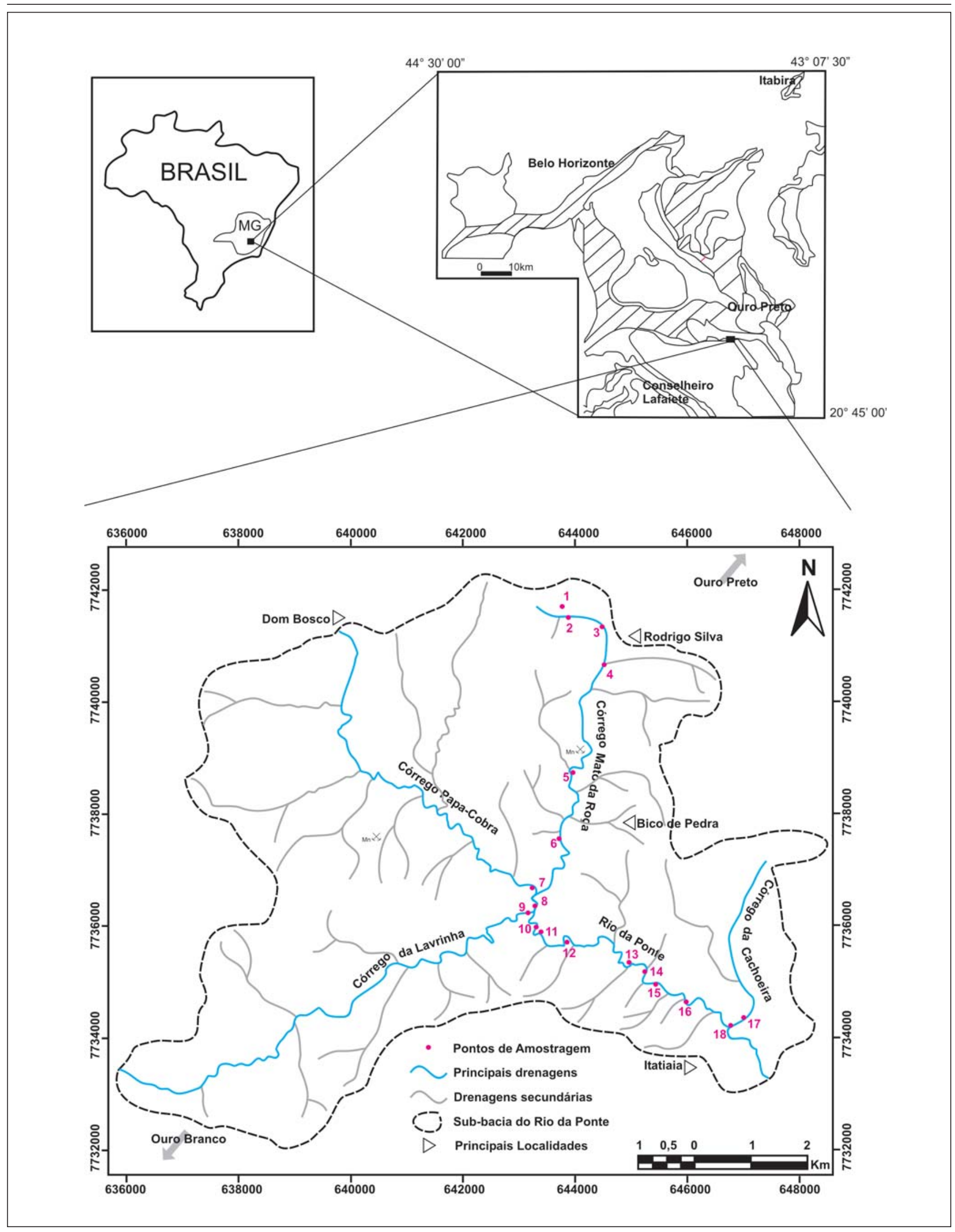

Figura 1 - Área de Estudo: Sub-bacia do rio da Ponte, Ouro Preto-MG. 
Tabela 1 - Parâmetros físico-químicos (agosto/2005 - estação de seca).

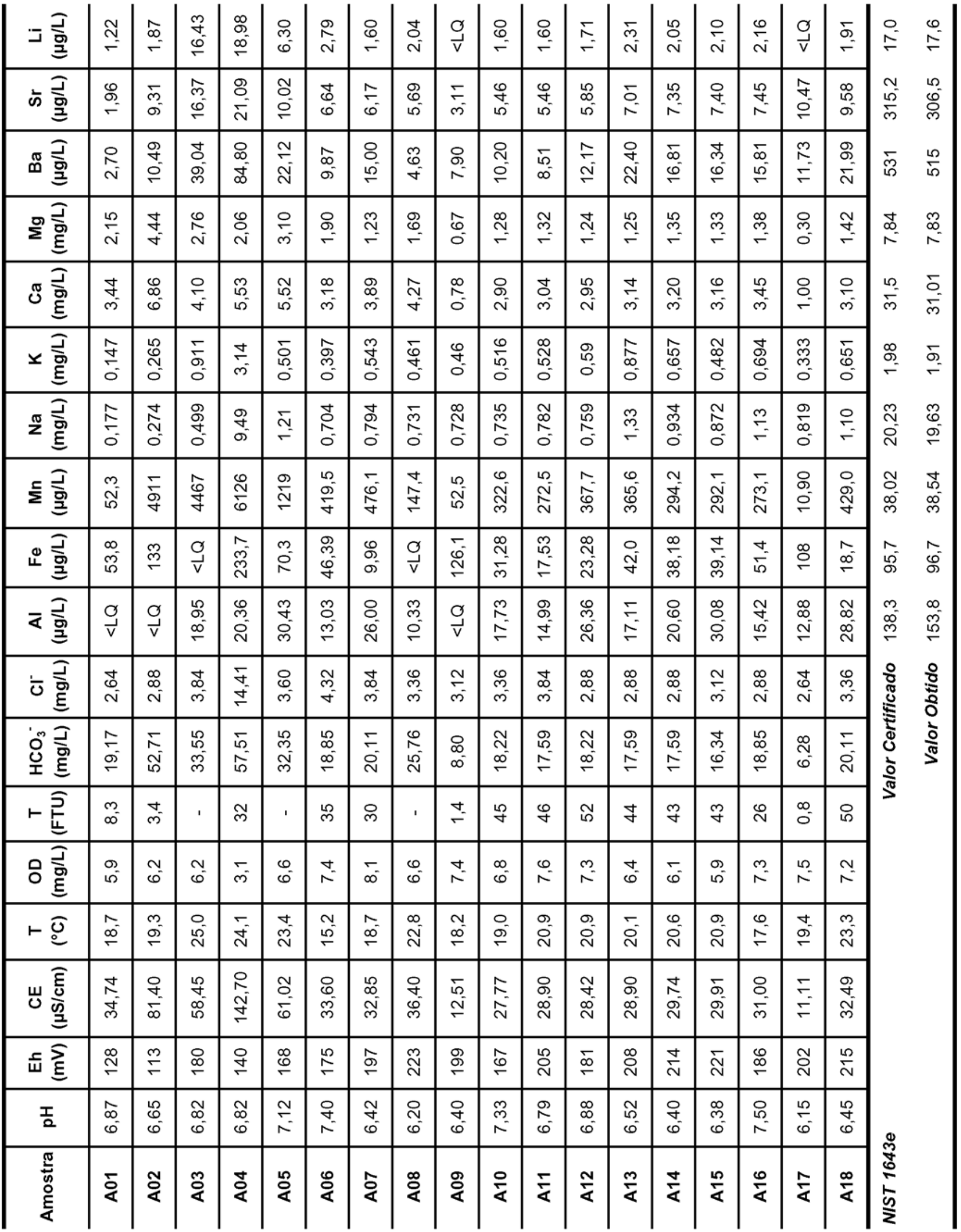


Tabela 2 - Parâmetros físico-químicos (abril/2006 - estação das chuvas).

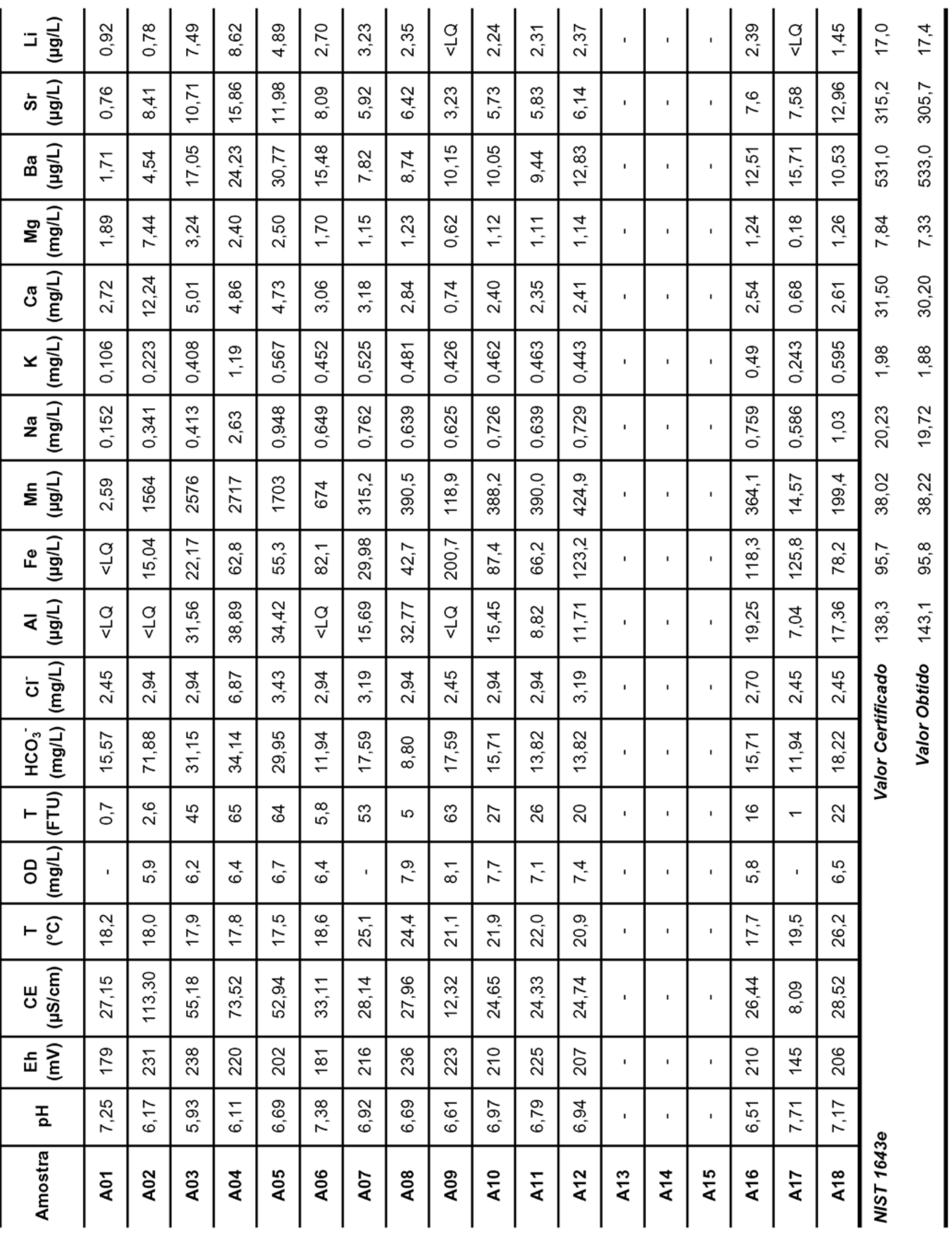


A condutividade elétrica (CE) pode ser utilizada como um parâmetro de avaliação das modificações na composição total das águas, pois ela reflete a quantidade de material dissolvido. São observados valores mais elevados de CE a montante (amostras A02 a A05). Esses sítios estão próximos do distrito de Rodrigo Silva e recebem as contribuições desta localidade. O valor mais crítico refere-se à amostra A04 (142,7 $\mu$ S.cm ${ }^{-1}$; seca), que é o primeiro sítio de amostragem a jusante de Rodrigo Silva e representa as contribuições totais do distrito. Os menores valores de CE nas duas estações são encontrados nas amostras A09 $\left(12,51 \mu\right.$ S.cm $\left.{ }^{-1} ; 8,20 \mu S . \mathrm{cm}^{-1}\right)$ e A17 $\left(11,11 \mu \mathrm{S} . \mathrm{cm}^{-1} ; 7,18 \mu \mathrm{S} . \mathrm{cm}^{-1}\right)$, dois tributários - córregos da Lavrinha e da Cachoeira -, que representam, visualmente, áreas com pouca interferência antrópica e águas límpidas. Os demais sítios amostrais apresentaram valores de CE em torno de $25 \mu \mathrm{S} . \mathrm{cm}^{-1}$.

Os teores de oxigênio dissolvido (OD) nas águas da sub-bacia do rio da Ponte variam de 3,1 a 8,1 mg.L-1 (estação de seca) e 5,9 a 8,1 mg. $\mathrm{L}^{-1}$ (estação das chuvas). A amostra A04 na estação de seca apresenta o valor mais crítico (3,1 mg. $\left.\mathrm{L}^{-1}\right)$. O recebimento das contribuições do distrito de Rodrigo Silva talvez seja o principal fator responsável pela diminuição do OD no sítio amostral. Com a introdução dos efluentes domésticos nas águas, o oxigênio dissolvido provavelmente é consumido, numa tentativa de manutenção do ecossistema aquático.

A turbidez expressa a quantidade de material em suspensão e pode ser usada como uma medida direta dessa quantidade. Os sólidos em suspensão, que são transportados pelas águas como silte, argila, detritos orgânicos e plâncton em geral - contribuem para a elevação da turbidez. A avaliação da turbidez é importante, pois ela influencia na intensidade de luz difundida e na absorção de calor no compartimento aquático. Altos valores de turbidez podem ocasionar aumento de temperatura, redução da luz disponível para as plantas com alteração na fotossíntese, além de interferir nos usos doméstico, industrial e re- creacional de um corpo d'água. Essa elevação da turbidez pode ser causada por erosão das margens dos rios e áreas adjacentes, crescimento excessivo de algas, alterações no fluxo do rio, efluentes domésticos e industriais (Chapman \& Kimstach, 1996; USEPA, 1997; Anderson, 2005; Murphy, 2006). Reis et al. (2003) observaram que as medições nefelométricas de amostras escuras contendo goethita e hematita aumentam até os valores de 55 e 29 FTU. A partir deste ponto, mesmo aumentando a quantidade do material em suspensão, observase uma diminuição do valor da turbidez. Segundo os autores, esses dois minerais são escuros e apresentam uma capacidade de reflexão diferente de um material mais claro, como a sílica. As amostras A03, A05 e A08 constituemse, visualmente, como as três amostras mais escuras, no entanto, têm-se baixos valores de turbidez nefelométrica (6, 19 e 0,1 FTU; respectivamente), daí seus valores não estarem registrados na Tabela 1. A distribuição dos valores de turbidez ao longo do curso do rio mostra um padrão aleatório e com altos valores. Alguns valores chegam a ultrapassar, em alguns pontos, o limite de 40 FTU estabelecido pela Resolução CONAMA $\mathrm{N}^{\circ} 357$ para águas Classe 1. Valores elevados de turbidez representam uma resposta à atividade garimpeira na área de estudo, que introduz uma quantidade significativa de sólidos em suspensão nos cursos d'água. Isto ocorre, tanto pela introdução direta devido ao peneiramento, lavagem de material e utilização de dragas, como, também, é uma conseqüência do desmatamento e decapeamento realizado durante a abertura das frentes de lavras que retiram a cobertura vegetal, facilitando a erosão e o transporte de sólidos.

Os valores mais elevados de alcalinidade são observados a montante e devem-se provavelmente à presença de dolomitos e filitos dolomíticos naquela região, cuja dissolução introduz bicarbonatos nas águas. Os valores da estação chuvosa são levemente inferiores, prevalecendo o efeito de diluição com as chuvas. A amostra A02 apresenta concentração mais alta no período das chuvas, que pode ser justificada pela diminuição do volume d'água naquele sítio amostral. Durante a amostragem na estação das chuvas, algumas áreas a montante desse ponto estavam em obras, provocando pequenos barramentos no córrego. As amostras A09 e A17, referentes a dois tributários, também apresentam maior alcalinidade na estação chuvosa. Os tributários drenam áreas com ocorrência de quartzitos, os córregos são encaixados e suas águas correm sobre rochas aflorantes formando pequenas cascatas. A turbulência das águas pode aumentar a taxa de gás carbônico $\left(\mathrm{CO}_{2}\right)$ dissolvido, podendo causar uma elevação da alcalinidade, principalmente no período das chuvas. A USEPA (United States Environmental Protection Agency) recomenda uma alcalinidade mínima de $20 \mathrm{mg} . \mathrm{L}^{-1}$ em termos de $\mathrm{CaCO}_{3}\left(24,4 \mathrm{mg} \cdot \mathrm{L}^{-1} \mathrm{em}\right.$ termos de $\mathrm{HCO}_{3}^{-}$), para que haja uma boa manutenção do sistema aquático. De acordo com esse parâmetro, apenas os sítios amostrais a montante $(02,03,04 \mathrm{e} \mathrm{05)}$ apresentariam uma boa manutenção do sistema aquático no caso de uma eventual introdução de substâncias ácidas no meio.

Segundo a CETESB (2006) a elevação da concentração de cloreto pode estar associada a contaminações provenientes de aterros sanitários, esgotos domésticos e lixões. Por isso, o cloreto pode ser considerado um indicador de contribuições antrópicas, apesar de existirem métodos mais indicados e precisos para esse tipo de contaminação como o teste de coliformes fecais. As maiores concentrações de cloreto são observadas na amostra A04 na estação seca e chuvosa (14,41 e 6,47 mg. $\mathrm{L}^{-1}$, respectivamente). Os demais sítios de amostragem apresentam uma distribuição uniforme com concentração média na estação seca e chuvosa de 3,26 e 2,86 mg. $\mathrm{L}^{-1}$, respectivamente. Esse aumento pode estar relacionado às contribuições antrópicas, uma vez que tal amostra foi coletada logo após o distrito de Rodrigo Silva. O sulfato encontra-se em concentrações inferiores a 1,0 mg. $\mathrm{L}^{-1}$ nas águas da sub-bacia do rio da Ponte, ou seja, menor que o limite de quantificação do método utilizado $(<\mathrm{LQ})$. 
Aline Kelly Guimarães-Silva et al.

\section{Composição Química}

Os elementos considerados nas análises são: Al, As, Ba, Ca, Cd, Co, Cr, $\mathrm{Cu}, \mathrm{Fe}, \mathrm{K}, \mathrm{Li}, \mathrm{Mg}, \mathrm{Mn}, \mathrm{Mo}, \mathrm{Na}, \mathrm{Ni}, \mathrm{Sc}, \mathrm{Sr}$, Ti, V, Y e Zn. Entre estes, alguns se encontram abaixo do limite de quantifica-

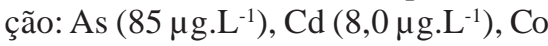
$\left(15 \mu g . L^{-1}\right), \operatorname{Cr}\left(15 \mu g . L^{-1}\right), \operatorname{Cu}\left(2,5 \mu g . L^{-1}\right)$,

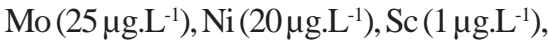
Ti $\left(1,5 \mu g . L^{-1}\right), V\left(10 \mu g . L^{-1}\right), Y\left(5,0 \mu g . L^{-1}\right)$ e $\operatorname{Zn}\left(5,0 \mu g . L^{-1}\right)$.

O alumínio apresenta uma distribuição aleatória ao longo dos sítios amostrados não sendo possível avaliar nenhum padrão de distribuição dos dados. Os menores valores quantificáveis de $\mathrm{Al}$ nas estações seca e chuvosa são, respectivamente, 10,30 e 8,82 $\mu \mathrm{g} . \mathrm{L}^{-1}$. Os valores máximos para as mesmas são de

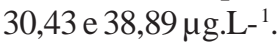

Ferro e Manganês, em geral, apresentam altas concentrações a montante, onde as concentrações da estação seca são mais altas do que as da estação chuvosa. Os resultados de Fe na estação de seca variam de $<6,00$ a 233,7 $\mu$ g. $L^{-1}$ e os da estação das chuvas variam de $<6,00$ a 200,7 $\mu \mathrm{g} . \mathrm{L}^{-1}$. Na estação das chuvas, as concentrações mais altas referem-se às amostras A09 e A17 (200,7 e 125,8 $\mu$ g.L - $^{-1}$; dois tributários - córregos da Lavrinha e da Cachoeira), e na estação da seca as maiores concentrações referem-se às amostras A02 e A04 (133,0 e 233,7 $\mu$ g.L - $^{-1}$; córrego Mato da Roça). Manganês apresenta altas concentrações ao longo de todos os sítios amostrais, principalmente a montante (A02, A03, A04 e A05). Os altos valores de Mn devem-se provavelmente à remobilização de material proveniente de antigos depósitos de ferro e manganês e também à existência de minas desativadas que se encontram na porção norte da área de estudo, próximos ao córrego Mato da Roça. As amostras A01-04, A07 e A18 apresentam concentrações da estação da seca superiores às da estação das chuvas, mostrando que prevalece o escoamento superficial nas áreas a montante, próximas aos locais dos depósitos e na área próxima à represa (A18). Nos demais sítios, a concentração da estação das chuvas é superior, prevalecendo o efeito de diluição.
Sódio e Potássio são os metais alcalinos mais importantes e abundantes nas águas naturais e, apesar de pertencerem ao mesmo grupo, eles apresentam propriedades diferentes (Santos, 1997). A distribuição geral desses elementos mostra concentrações mais baixas nos três primeiros sítios amostrais, porém crescente com concentração máxima na amostra A04. Em geral, a concentração na estação das chuvas é inferior à estação da seca, prevalecendo o efeito da diluição. Novamente, a amostra A04 se destaca, por apresentar uma concentração superior às demais. Grande parte do sódio presente nas águas naturais do local deve ser proveniente da troca iônica natural nos minerais que o contêm e da lixiviação dos feldspatos e outros silicatos, mas pode também representar indício de atividade antrópica. O potássio também apresenta intensa participação nos processos de troca iônica, além de grande facilidade de ser adsorvido pelos argilominerais. Muito importante no desenvolvimento das plantas, ele é comumente adicionado aos solos como fertilizante. Suas fontes naturais incluem os feldspatos e micas de rochas ígneas e metamórficas (Hounslow, 1995; Santos, 1997).

Cálcio e Magnésio são metais alcalino-terrosos que apresentam propriedades similares, porém o magnésio é mais solúvel e mais difícil de precipitar, tendendo a permanecer em solução. Os sais de cálcio apresentam solubilidade moderada a elevada, sendo comum a precipitação como carbonato de cálcio $\left(\mathrm{CaCO}_{3}\right)$. São elementos predominantes nas águas naturais e responsáveis pela dureza das mesmas (Santos, 1997; Weiner, 2000). Esses elementos apresentam concentrações mais altas a montante (A01- A05). A concentração na estação das chuvas é inferior à da estação seca, exceto nas amostras A02, A03 (para Ca e Mg) e A04 (para Mg). Essas amostras apresentam concentrações da estação chuvosa superiores, principalmente na amostra A02. Nesses locais, o efeito do escoamento superficial prevalece, provavelmente por causa da geologia da região, com presença de rochas carbonáticas que estão sujeitas à lixiviação pelas águas e liberação de Ca e Mg. Esses resultados estão associados com as concentrações mais altas de $\mathrm{HCO}_{3}^{-}$, já discutidas para alcalinidade.

Lítio, Bário e Estrôncio são considerados elementos menores nas águas naturais. Não são elementos que estão presentes em todas as águas (como, por exemplo, Na-K-Ca-Mg), mas podem ser encontrados em concentrações consideráveis (Hounslow, 1995). Os três elementos apresentam a mesma distribuição com concentrações maiores a montante (A03 e A04), onde as concentrações da estação seca são muito superiores às da estação chuvosa. Nas demais amostras, em geral, as concentrações da estação chuvosa são superiores ou equivalentes às concentrações da estação seca.

\section{Estimativa do material particulado em suspensão}

A separação da fase dissolvida e do material particulado em suspensão (MPS) pode ser feita por um simples processo de filtração, utilizando membranas com poros de 0,45 $\mu$ m (Hem, 1985; Carvalho et al., 1999;Salomão et al., 2001; Sokolowski et al., 2001; Gagnon \& Saulnier, 2003; Lee et al., 2003; Nguyen et al., 2005).

Tendo em vista a intensa atividade dos garimpos na área de estudo, esta avaliação teve por objetivo identificar os locais com maior quantidade de MPS e, também, auxiliar nas conclusões dos demais resultados obtidos. Desse modo, os dados obtidos são utilizados unicamente para comparação entre os pontos e associação com a presença ou ausência de garimpos durante a amostragem. Não devendo ser comparados com outros dados que sejam apresentados na literatura.

As amostras que apresentam maior quantidade de material particulado em suspensão foram coletadas justamente após focos de intensa atividade garimpeira. As amostras A03 e A09 apresentam maior quantidade de MPS na estação da seca. Para a estação das chuvas, a amostra A03 se mantém com maior 
A qualidade das águas na região dos garimpos de topázio imperial na sub-bacia do Rio da Ponte...

quantidade de MPS e destaca-se a contribuição do córrego Papa-Cobra (sítio 07). Esse sítio representa as contribuições desse córrego, com presença de grandes lavras de topázio a montante Vermelhão e Capão do Lana-, além dos garimpos de leito e de margem, que, de acordo com as descrições de garimpeiros, também estão presentes ao longo desse tributário.

Quando o garimpo está em atividade, a água apresenta uma coloração mais avermelhada, devido à grande quantidade de material particulado introduzido. A amostra de água do sítio amostral (08), na estação de seca, foi amostrada justamente por perceber o funcionamento da draga em um garimpo de margem e mudança imediata na qualidade da água.

A concentração de sólidos totais em suspensão em um rio, sem nenhuma influência antrópica, aumenta em função do fluxo. As partículas são derivadas dos bancos dos rios e da erosão de áreas adjacentes, além da ressuspensão do material depositado nas margens e leitos dos rios. As taxas de erosão estão associadas ao clima, particularmente à quantidade e intensidade das chuvas, e podem ser influenciadas pela cobertura vegetal. O desmatamento e as atividades antrópicas dentro de uma bacia de drenagem podem resultar em uma maior taxa de erosão e, conseqüentemente, em um aumento significativo na taxa de material em suspensão transportado (Meybeck et al., 1996).

No caso da sub-bacia do rio da Ponte, deve-se considerar o efeito dos fatores naturais e antrópicos, na quantidade de material particulado nas águas. Considera-se que a quantidade de MPS é altamente influenciada pela presença dos garimpos, ressaltando que os garimpos são atividades migratórias e sazonais. Desta forma, os dados obtidos representam apenas um registro do momento da amostragem (Tabela 1).

\section{Conclusões}

As águas da sub-bacia do rio da Ponte apresentam uma variação sazonal pequena para os parâmetros físico-químicos e metais dissolvidos avaliados. As principais influências observadas para as águas do rio da Ponte são: (i) os depósitos de ferro-manganês e antigas minas de manganês na porção norte da área de estudo; (ii) o distrito de Rodrigo Silva e suas contribuições; e (iii) os garimpos de topázio localizados ao longo de toda a área. Cada uma dessas influências apresenta contribuições específicas, que merecem ser ressaltadas.

Segundo Johnson (1962), dois tipos de depósito de manganês são encontrados na área: (1) concentração supergênica de manganês a partir de camadas de manganês intercaladas com itabirito e dolomita, e (2) pequenos depósitos formados pela concentração supergênica de manganês derivado de rochas clásticas/detríticas. Foram identificadas elevadas concentrações de manganês ao longo do curso principal amostrado, que podem estar associadas a esses depósitos. As concentrações de manganês ultrapassam os limites estabelecidos pela Resolução CONAMA N 357 e os sítios mais críticos estão localizados a montante.

O elevado valor para condutividade elétrica (142,70 $\mu \mathrm{S} . \mathrm{cm}^{-1}$; seca) e a baixa quantidade de oxigênio dissolvido (3,1 mg. $\mathrm{L}^{-1}$; seca) nas amostras A03 e A04 estão associados às contribuições antrópicas provenientes do distrito de Rodrigo Silva. Essas amostras também apresentam as maiores concentrações de sódio, potássio e cloreto, que também podem ser considerados indicativos desse tipo de contribuição.

Quanto aos garimpos de topázio localizados ao longo de toda a área de estudo, pode-se dizer que a principal influência para o compartimento aquático é a introdução de sólidos em suspensão. Como o processo de extração mineral é puramente físico, não envolvendo nenhuma adição de produto químico, sua contribuição para os cursos d’água são os rejeitos sólidos. O material geológico consolidado é desagregado e introduzido nas águas, logo são submetidos a diferentes condições físico-químicas, que podem induzir à liberação ou ao acúmulo de espécies químicas.
Tabela 3 - Estimativa da quantidade de material particulado em suspensão $\left(\mathrm{mg} \cdot \mathrm{L}^{-1}\right)$, na estação seca e chuvosa.

\begin{tabular}{|c|c|c|}
\hline \multirow{2}{*}{ Ponto } & \multicolumn{2}{|c|}{$\operatorname{MPS}\left(\mathrm{mg} \cdot \mathrm{L}^{-1}\right)$} \\
\hline & Seca & Chuvas \\
\hline A01 & 95,19 & $<\mathrm{LQ}$ \\
\hline A02 & $<\mathrm{LQ}$ & $<\mathrm{LQ}$ \\
\hline $\mathrm{A} 03$ & 1661 & 840 \\
\hline A04 & $<\mathrm{LQ}$ & 314,5 \\
\hline A05 & 41,58 & 78,3 \\
\hline A06 & 574,8 & $<\mathrm{LQ}$ \\
\hline $\mathrm{A} 07$ & 687,5 & 277,7 \\
\hline A08 & 2931 & 258,3 \\
\hline A09 & $<\mathrm{LQ}$ & $<\mathrm{LQ}$ \\
\hline A10 & 258,6 & $<\mathrm{LQ}$ \\
\hline A11 & 245 & 40,7 \\
\hline $\mathrm{A} 12$ & 358,3 & $<\mathrm{LQ}$ \\
\hline A13 & 157,9 & - \\
\hline A14 & 121 & - \\
\hline A15 & 118,6 & - \\
\hline A16 & $<\mathrm{LQ}$ & $<\mathrm{LQ}$ \\
\hline A17 & $<\mathrm{LQ}$ & $<\mathrm{LQ}$ \\
\hline A18 & 464,5 & $<\mathrm{LQ}$ \\
\hline
\end{tabular}

NOTA: $L Q=$ Limite de Quantificação

$L Q=38 \mathrm{mg} \cdot \mathrm{L}^{-1}$

\section{Agradecimentos}

Os autores agradecem à CAPES e ao CNPq pelas bolsas concedidas, ao Projeto de Cooperação Internacional Brasil e Alemanha 162/03 (CAPES/DAAD) e ao Laboratório de Geoquímica Ambiental (LGqA/DEGEO/UFOP).

\section{Referências bibliográficas}

ANDERSON C.W. Field measurements. In: WILDE, F.D. (Ed.). National Field Manual for the Collection of WaterQuality Data. USGS. 2005 Disponível em: $<$ http://water.usgs.gov > Acesso em: 02/nov./2006.

BOURG A.C.M., LOCH J.P.G. Mobilization of heavy metals as affected by $\mathrm{pH}$ and 
Aline Kelly Guimarães-Silva et al.

redox conditions. In: SALOMONS, W. \& STIGLIANI, W.M. (Eds). Biogeodynamics of pollutants in soils and sediments: risk assessment of delayed and non-linear responses. Springer, Germany. p. 87-102, 1995.

CARVALHO C.E.V., OVALLE A.R.C., REZENDE C.E., MOLISANI M.M., SALOMÃO M.S.M.B., LACERDA L.D. Seasonal variation of particulate heavy metals in the lower Paraíba do Sul River, R.J., Brazil. Environmental Geology, v. 37, n.4, p.297-302, 1999.

CHAPMAN P.M., WANG F., JANSSEN C., PERSOONE G., ALLEN H.E. Ecotoxicology of metals in aquatic sediments: binding and release, bioavailability, risk assessment, and remediation. Canadian Journal of Fisheries and Aquatic Science. v. 55, n.10, p. 2221-2243, 1998.

CONAMA, 2005. Resolução Nº 357.

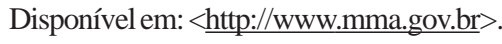
Acesso em: 24/set/2006.

CUSTODIO E. Hidrogeoquímica. In: CUSTODIO, E. \& LLAMAS, M.R. Hidrogeologia Subterrânea. $2^{\mathrm{a}}$ Ed., Barcelona, v.2, p. 1008-1018, 1983.

GAGNON C., SAULNIER I. Distribution and fate of metals in the dispersion plume of a major municipal effluent. Environmental Pollution, v. 124, n.1, p. 47-55, 2003.

GILL R. Chemical fundamentals of geology. $2^{\mathrm{a}}$ Ed. London: Chapman \& Hall, 1996. 298 p.

GREENBERG A.E., CLERESCI L.S., EATON A.D. (Eds.). Standard methods for the examination of water and Wastewater. $18^{\mathrm{a}}$ Ed. Washington DC: American Public Health Association APHA, 1992.

GUIMARÃES A. T. A. Avaliação geoquímica ambiental da barragem do Ribeirão da Cachoeira, Ouro Preto, Sudeste do Quadrilátero Ferrífero, MG.
Ouro Preto: Departamento de Geologia, Universidade Federal de Ouro Preto, Contribuições à Ciências da Terra, Série M, v.27, n. 239, 111 p., 2005. (Dissertação de Mestrado).

HEM J. Study and interpretation of chemical characteristics of natural water. $3^{\text {a }}$ Ed. U.S. Geological Survey, Water-Supply Paper 2254. 1985.

HOUNSLOW, A W. Water quality data: analysis and interpretation. Boca Raton: Lewis Publishers, 1995. 397 p.

JOHNSON R.F. Geology and ore deposits of the Cachoeira do Campo, Dom Bosco, and Ouro Branco Quadrangles Minas Gerais, Brazil. Geological Survey Professional Paper 341-B. DNPM/USGS, Washington: 1962.

LEE S., MOON J.W., MOON H.S. Heavy metals in the bed and suspended sediments of Anyang River, Korea: Implications for water quality. Environmental Geochemistry and Health, v. 25, n. 4, p.433-452, 2003.

MEYBECK M., FRIEDRICH G., THOMAS R., CHAPMAN D. 1996. Rivers. In: CHAPMAN, D. (Ed.) Water quality assessments - a guide to use of Biota, sediments and water in environmental monitoring. $2^{\text {a }}$ Ed. Cambridge: UNESCO/WHO/UNEP. 626p.

MURPHY, S. General information in turbidity. City of Boulder/USGS/Water Quality Monitoring. Disponível em: http://bcn.boulder.co.us/basin/data/BACT/info/Turb.html. Acessado em 02/nov./ 2006.

NGUYEN H.L., LEEMAKERS M., OSÁN J., TÖRÖK S., BAEYENS W. Heavy metals in Lake Balaton: water column, suspended matter, sediment and biota. The Science of the Total Environment, v. 340, n. 1/3, p.213-230, 2005.

PEIXOTO, R.J., LIMA, H.M. Diagnóstico dos garimpos de topázio imperial no Alto Maracujá, Sub-bacia do rio da Velhas, MG. REM - Revista da Escola Minas de Minas, v. 57, n. 4, p. 249-254, 2004.

REIS, E.L., DE LENA, J.C., GUEDES, C.D. A medição da turbidez em suspensões contendo partículas escuras (goethita e hematita). In: ASSOCIAÇÃO BRASILEIRADE QUÍMICA, Anais... v. 52, n. 3, p. 102-104, 2003.

SALOMÃO, M.S.M.B., MOLISANI, M.M., OVALLE, A.R.C., REZENDE, C.E., LACERDA, L.D., CARVALHO, C.E.V. Particulate heavy metal transport in the lower Paraíba do Sul River basin, southeastern, Brasil. Hydrological Processes, v. 15, n. 4, p. 587-593, 2001.

SANTOS, A.C. Noções de hidrogeoquímica. In: FEITOSA, F.A.C., MANUEL FILHO, J. Hidrogeologia conceitos $\boldsymbol{e}$ aplicações. Fortaleza:CPRM/LABHID/UFPE, p. 81-108. 1997.

SIEGEL, F.R. Environmental geochemistry of potencially toxic metals. Berlin: SpringerVerlag, 2002. $218 \mathrm{p}$.

SOKOLOWSKI A., WOLOWICZ M., HUMMEL H. Distribution of dissolved and labile particulate trace metals in the overlying bottom water in the Vistula River plume (Southern Baltic Sea). Marine Pollution Bulletin, v. 42, n.10, p. 967-980, 2001.

USEPA (United States Environmental Protection Agency). Monitoring water quality. Volunteer stream monitoring: a methods manual. Office of Water 4503F. EPA 841 B 97 003. 1997.

WEINER E. R. Applications of environmental chemistry: a practical guide for environmental professionals. Florida: CRC Press, Lewis Publishers, 2000. 288 p.

Artigo recebido em 01/02/2007 e aprovado em 06/06/2007.

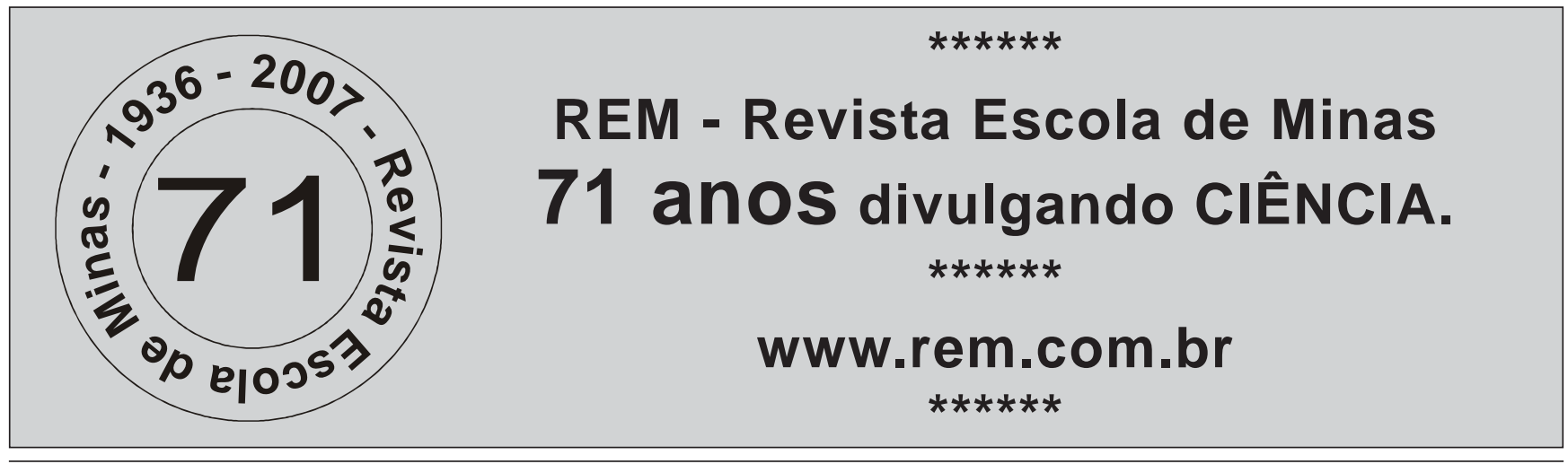

REM: R. Esc. Minas, Ouro Preto, 60(4): 603-611, out. dez. 2007611 